
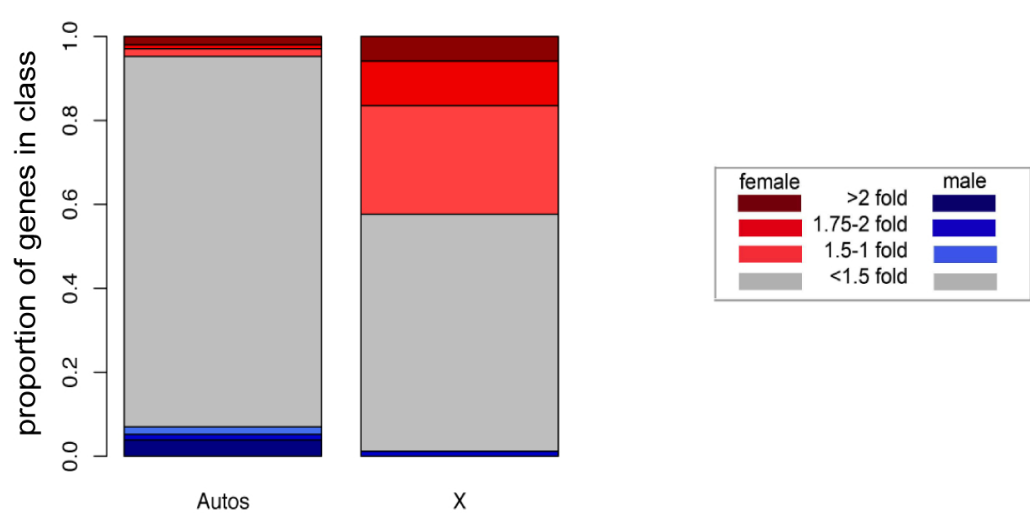

B
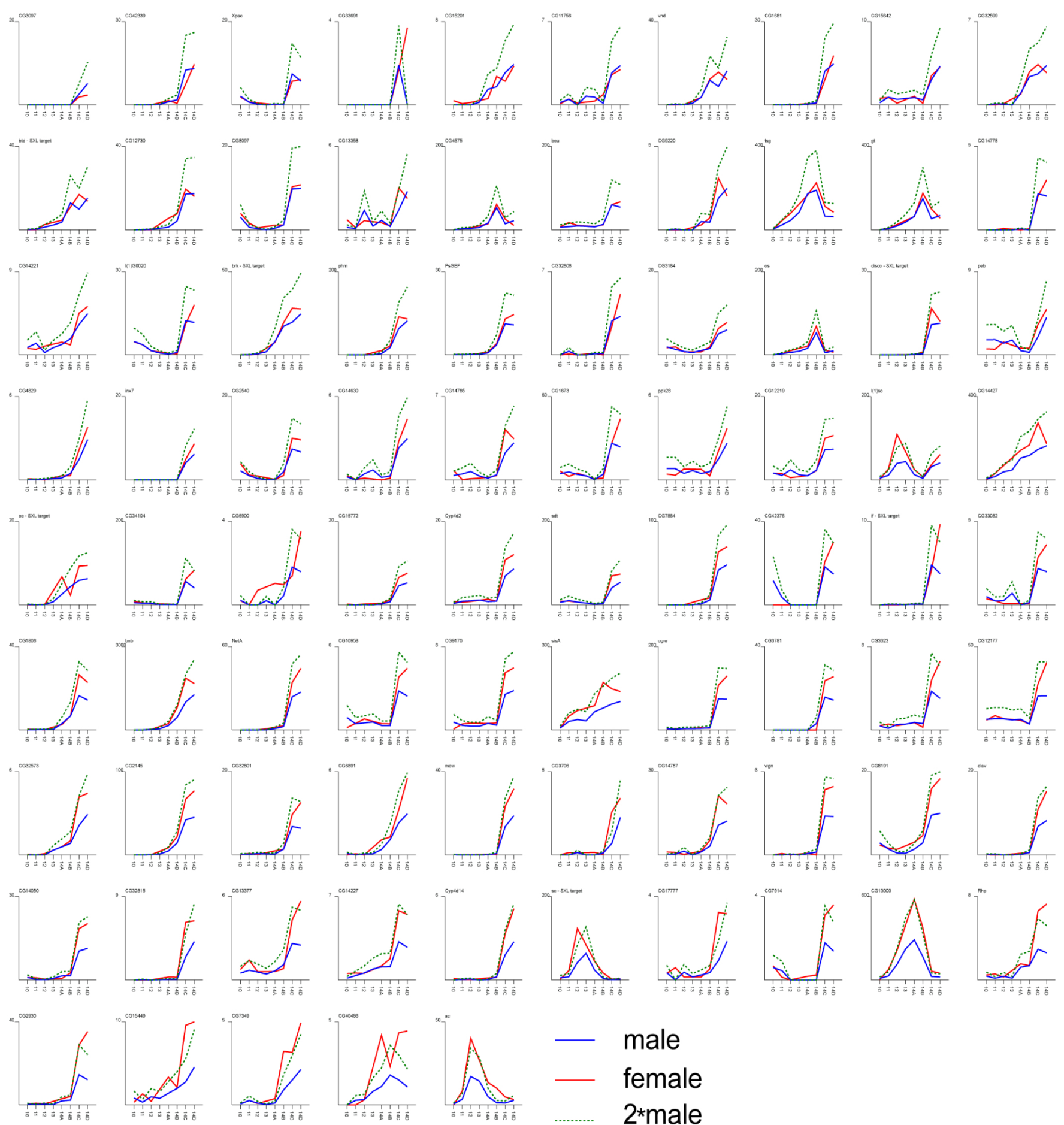

\title{
- male
}

_ female 
Supplemental Figure 1. Extent of dosage compensation for zygotic genes on the $\mathbf{X}$ chromosome. Each gene was assigned a female to male (F:M) ratio score equal to the slope of the line fit (by least squares) to the male and female transcript levels for that gene over all timepoints. A) Proportion of genes with F:M ratios between 1.0 (equal expression in males and females) and 2.0 (twice expression in females) B) Transcript abundance timeseries for zygotic genes on the $\mathrm{X}$ chromosome, in female and male embryos, over all timepoints. Genes sorted by F:M ratio. 